\title{
Clinical Course Development of the Chagas Heart Disease in a Brazilian Patient: A Case Report
}

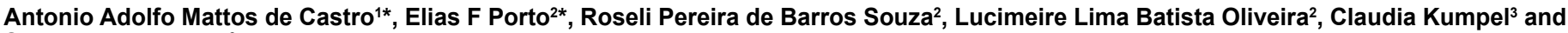 \\ Sergio Mitio Tagami ${ }^{3}$ \\ ${ }^{1}$ Department of Physiotherapy at the Federal University of Pampa (Unipampa), Rio Grande do Sul, Brazil \\ ${ }^{2}$ Pulmonary Rehabilitation Center at the Adventist University of Sao Paulo (Unasp), Sao Paulo, Brazil \\ ${ }^{3}$ Adventist University of Sao Paulo (Unasp), Sao Paulo, Brazil
}

\begin{abstract}
Chagas disease (CD) was firstly discovered by the Brazilian physician Carlos Chagas in 1909. It is an endemic condition caused by a protozoan named Trypanosome cruzi and it is transmitted by the popularly known barber mosquito. The major $C D$ transmission modes to man are blood transfusion or congenital pathways; minor $C D$ transmission modes are organ transplantation, accidental and oral forms. Oral transmission is being considered the main pathway responsible for several outbreaks of $C D$ in Brazil mainly in the Amazon region where 41 cases have been registered in the year of 2011 associated with the acaí intake. This epidemiologic cause occurs due to the instalment of the barber in lowland areas where the acaí is harvested; this, associated to poor fruit handling and hygiene, the final consumption is ought to be contaminated. The patient in this case study was chosen for the particular reason that this form of Chagas transmission is one of the least prevalent seen worldwide. Our study aimed to show the eight years length clinical course of a patient with Chagas disease.
\end{abstract}

Keywords: Cardiac rehabilitation; Heart disease; Edema

\section{Case Study}

This patient was referred to the cardiac rehabilitation outpatient clinic of our university. He was diagnosed of Chagas disease eight years ago and presented symptoms of overall fatigue, minimum efforts dyspnea, lower extremities edema, chest pain and dry cough. Firstly, every previous examinations and tests of the patient was assessed and registered in a medical file. Secondly, we conducted a physical, body composition (bioelectrical impedance analysis), quality of life (Minnesota questionnaire) and six minutes walking test assessments. All these tests we performed by the time of cardiac rehabilitation program entrance in our facility during the year 2014. No previous data of quality of life or functional capacity was registered prior to the patient's admission in our rehabilitation facility. Nevertheless, our patient walked 530 meters in the six minutes walking test (Figure 1) and scored 6 points at the Minnesota questionnaire [1-5].

\section{Patient's Background and Disease History}

Patient initials are V.M.S. and he is a 60 years old male, natural of

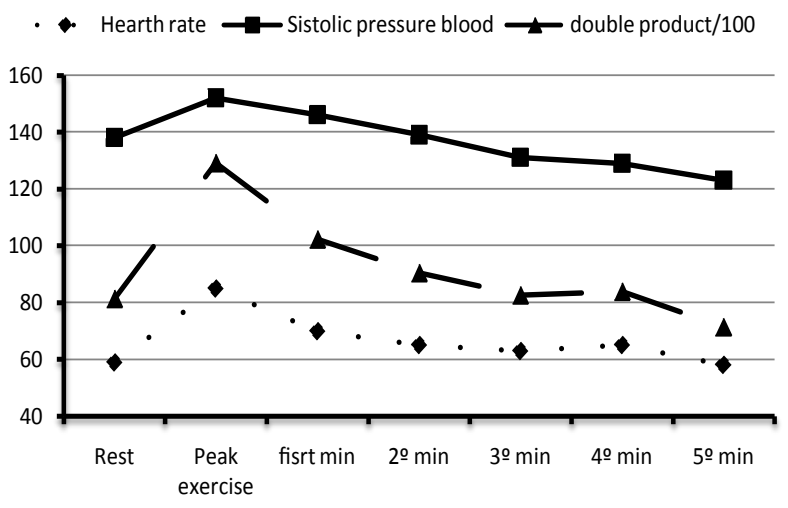

Figure 1: Functional capacity assessment during the six minutes walking test (six minutes walking test distance comprised $530 \mathrm{~m}$ ) accomplished in the year 2014 .
Utinga BA, is catholic religion oriented with an incomplete high school educational background, works as a baker, currently lives in Embu of Arts-Sao Paulo in a two bedroom townhouse with his wife and five children. A report having enough period of sleep either at night and/or during the day when he feels the need to Patient also reports a proper food intake preferably with the ones with low potassium content. On the other hand enough body hydration was lacking and he was instructed to its importance especially with the diagnosis of pre-renal failure almost setting in. After diagnose no smoking and/or drinking intake was done even with his previous personal history of smoking and drinking for twenty and seven years, respectively. Throughout his life he has never performed any comprehensive physical activity such as walking or pedaling. Currently weights $55 \mathrm{~kg}$ and heights $1.65 \mathrm{~m}$. His body mass index (BMI) is $20.2 \mathrm{kgm}^{2}$ and presents normal blood pressure (120 over $80 \mathrm{mmHg}$ of systolic and diastolic pressures). All current patient's body composition data can be seen on table 1 .

At the age of 52 years old our studied patient was diagnosed with Chagas dilated cardiomyopathy disease. One year after diagnosis he initially developed fatigue and dyspnea at maximum efforts which increased to minimum efforts, lower limbs edema, chest pain and cough without sputum production that persisted for a week. On March 2007 he had his first hospitalization due to severe chest pain that lasted five consecutive days. After discharge he was advised to seek follow up with a cardiologist.

*Corresponding authors: Elias Ferreira Porto, Pulmonary Rehabilitation Center at the Adventist University of Sao Paulo (Unasp), Sao Paulo, Brazil, Tel: 5511 968244412; E-mail: eliasfporto@gmail.com

Antonio Castro, Pulmonary Rehabilitation Center at the Adventist University of Sao Paulo (Unasp), Sao Paulo, Brazil, Tel: 5511 968244412; E-mail: antonioamcastro@yahoo.com.br

Received October 15, 2014; Accepted November 17, 2014; Published November 19, 2014

Citation: Castro AAM, Porto EF, Souza RPB, Oliveira LLB, Kumpel C, et al. (2014) Clinical Course Development of the Chagas Heart Disease in a Brazilian Patient: A Case Report. J Clin Case Rep 4: 449. doi:10.4172/2165-7920.1000449

Copyright: (c) 2014 Castro AAM, et al. This is an open-access article distributed under the terms of the Creative Commons Attribution License, which permits unrestricted use, distribution, and reproduction in any medium, provided the original author and source are credited. 


\begin{tabular}{|l|c|c|c|}
\hline Variables/Year & $\mathbf{2 0 0 7}$ & $\mathbf{2 0 0 8}$ & $\mathbf{2 0 1 4}$ \\
\hline Aortic root $(\mathrm{mm})$ & 30 & 33 & 31 \\
\hline Left atrium $(\mathrm{mm})$ & 37 & 36 & 45 \\
\hline End-diastolic diameter $(\mathrm{mm})$ & & 68 & 66 \\
\hline End-systolic diameter $(\mathrm{mm})$ & & 56 & 59 \\
\hline Left ventricular ejection fraction $(\%)$ & 36 & & 32 \\
\hline End-diastolic volume (ml) & 239 & & 224 \\
\hline Volume ratio mass (\%) & 0.77 & & 1.04 \\
\hline Pulmonary artery pressure (mmHg) & & & 54 \\
\hline
\end{tabular}

Table 1: Patient's current body composition data.

\begin{tabular}{|l|c|c|c|}
\hline Variables & Kg & Percentage & \\
\hline Body cell mass & 22.3 & 40.5 & \\
\hline Extracellular mass & 27.2 & 49.3 & \\
\hline Fat free mass & 49.5 & 89.8 & \\
\hline Fat mass & 5.6 & 10 & \\
\hline Intracellular fluid & 19.7 & 54.3 & \\
\hline Extracellular fluid & 16.6 & 45.7 & \\
\hline Total body fluid & 36.3 & 100 & \\
\hline TBW lean mass & & 73.3 & \\
\hline TBW total weight & & 65.9 & \\
\hline Muscle mass & 29 & 52.6 & \\
\hline Body mass index (kg/m $\left.{ }^{2}\right)$ & & & 10.7 \\
\hline Basal metabolic measure (cals) & & & 1544 \\
\hline
\end{tabular}

TBW=Total Body Water

Table 2: Patient's echocardiogram variables displayed over time.

\begin{tabular}{|l|c|c|c|}
\hline Variables/Year & $\mathbf{2 0 0 8}$ & $\mathbf{2 0 1 2}$ & $\mathbf{2 0 1 4}$ \\
\hline Total cholesterol (mg/dl) & 250 & 205 & 168 \\
\hline High density lipoprotein $(\mathrm{mg} / \mathrm{dl})$ & 65 & 54 & 35 \\
\hline Low density lipoprotein $(\mathrm{mg} / \mathrm{dl})$ & 154 & 136 & 108 \\
\hline Triglycerides $(\mathrm{mg} / \mathrm{dl})$ & 138 & 66 & 125 \\
\hline Glycaemia $(\mathrm{mg} / \mathrm{dl})$ & 423 & 124 & 161 \\
\hline Glycated hemoglobin (\%) & & 5.6 & 7.0 \\
\hline Hemoglobin $(\mathrm{mg} / \mathrm{dl})$ & 15.6 & 13.5 & 11.3 \\
\hline Hematocrit $(\%)$ & 44.9 & 39 & 32.9 \\
\hline
\end{tabular}

Table 3: Patient's laboratory blood tests displayed over time.

After the first appointment with the cardiologist a set of tests were taken. The echocardiogram showed that there was a dilated cardiomyopathy with left ventricular (LV) diastolic dysfunction (Table 2). Also, indirect immunofluorescence confirmed the positive serology for Chagas disease. At this point the patient began treatment with the following medications and initial doses: digoxin $(0,125 \mathrm{mg})$, carvedilol $(3,125 \mathrm{mg})$, monochord (40 mg) and furosemide (40 mg).

Patient heath status improved, however, in the early 2008 he was again admitted to a hospital diagnosed with hepatitis; on July 2008 he presented significant weight loss accompanied by extreme sweating and polydipsia. Rapid counting glucose examination was performed and a value of $423 \mathrm{mg} / \mathrm{dL}$ was found (Table 3). After two repeated tests similar values were found and the type II diabetes diagnosis was confirmed. Human insulin treatment taken once a day was initiated. After two months of treatment the patient showed insulin rejection. As an alternative treatment to human insulin the patient started taking glibenclamide and accomplished dietary control. On the years between 2009 and 2014 the patient showed clinical stability with no test alteration. By mid-2014 the tests showed a loss in the ejection fraction percentage, pulmonary arterial hypertension development (Table 2), increased serum potassium (Table 4) and weight loss. Exams such as colonoscopy and endoscopy were carried out but no colon and/or

\begin{tabular}{|l|c|c|c|c|}
\hline Variables/Year & $\mathbf{2 0 0 8}$ & $\mathbf{2 0 1 1}$ & $\mathbf{2 0 1 3}$ & $\mathbf{2 0 1 4}$ \\
\hline Urea $(\mathrm{mg} / \mathrm{dl})$ & & 38 & 45 & 42 \\
\hline Creatinine $(\mathrm{mg} / \mathrm{dl})$ & & 0.95 & 1.2 & 1.5 \\
\hline Potassium $(\mathrm{mmol} / \mathrm{L})$ & 5.0 & 4.7 & 5.5 & 5.9 \\
\hline Sodium $(\mathrm{mmol} / \mathrm{L})$ & & 140 & 140 & 137 \\
\hline
\end{tabular}

All variables represent serum samples.

Table 4: Patient's kidney function trend displayed over time.

esophagus injuries were seen. Our study case patient showed a typical over time Chagas disease presentation.

\section{Final Considerations}

The main findings of this case study are: there was a worsening of the patient's cardiac function over the eight years after diagnosis (seen by left atrium diameter increase and left ventricular ejection fraction decrease) as well as pulmonary hypertension development (Table 2); also the patient developed kidney disease seen by increased serum potassium value (Table 4).

The first report on human Chagas disease is dated back to the pre-Columbian American period and is considered as a poverty disease since it is mainly associated with poor housing conditions [6]. Nowadays there is no cure and the current drugs available for treatment present severe side effects and are not effective for treating all cases. Chagas disease currently affects about 12 million people in poor regions of 21 countries of the Latin America. In Brazil, it is estimated that 1.6 million patients are infected [7].

Chagas disease can affect the heart, esophagus and bowel systems. Normally these organs swell and lose normal function. Nevertheless, the heart is the targeted system with the development of congestive heart failure, whose symptoms are shortness of breath, heart palpitations and feet swelling [8]. Heart impairment may also occur on its nerves leading to varying degrees of heart blocks which, in some cases, may be indicative of pacemaker implantation [9].

Andrade [7] aimed to evaluate the effects of chemotherapy in patients with Chagas disease. They found that bezonidazol has beneficial effects once the tested patients showed no electrocardiographic changes and serology reduction in seven years of follow-up. Although the authors did not comment on patient's kidney function we call attention to the possible complications these patients can develop over time.

The year 2009 marks the 100 years of the disease discovery. Even so, after more than 100 years after its discovery we still are no way near to reach the disease cure. Nevertheless, most studies show that there are good therapeutic approaches to control its clinical side effects, however, not the prognosis. Currently, the main recommendations for these patients is lifestyle change by adopting any regular physical activity, good dietary practices and enough resting $[6,10]$.

\section{Conclusion}

Although the patient presented a health status considered as clinically stable there was a worsening of the patient's cardiac function over the eight years after diagnosis as well as pulmonary hypertension. Alongside with the patient's heart deterioration, the development and progression of a kidney dysfunction was seen over time.

\section{References}

1. Cavalcante LPG, Rolin DB, Pires Neto RJ, Vilar DCLF, Nogueira JOL (2009) Microepidemia de doença de chagas aguda por transmissão oral no Ceara. Cad. Saúde Col 17: 911-921.

2. Ministério da Saúde Secretaria de Vigilância em Saúde (2005) Brazilian 
Citation: Castro AAM, Porto EF, Souza RPB, Oliveira LLB, Kumpel C, et al. (2014) Clinical Course Development of the Chagas Heart Disease in a Brazilian Patient: A Case Report. J Clin Case Rep 4: 449. doi:10.4172/2165-7920.1000449

Consensus on Chagas disease. Rev Soc Bras Med Trop 38 Suppl 3: 7-29.

3. Chieff PP, Amato Neto V (2000) Prevention relating to alternative modes of transmission of Trypanosoma cruzi . Sao Paulo.

4. Andrade JP, Marin Neto JA, Paola AA, Vilas-Boas F, Oliveira GM et al. (2011) I Latin American Guidelines for the diagnosis and treatment of Chagas' heart disease: executive summary.. Arq Bras Cardiol 96: 434-442.

5. Dias LC, Dessoy M A, Silva JJN, Thiemann OH, Oliva G (2009) Chemotherapy of Chagas disease. State of the art and perspectives in the development of new drugs. Quim 32: 2444-2457.

6. Malafaia G, Rodrigues AS (2010) Centenary of the discovery of Chagas disease: challenges and prospects. Rev Soc Bras Med Trop 43: 483-485.
7. Monica Coelho Andrade (2013) Electrocardiographic response assessment and serological treatment with benznidazole in patients in the chronic phase of Chagas disease. Ceara Federal University Department of pathology and forensic medicine graduate program in pathology. Fortaleza.

8. Budni P, Pedrosa RC, Garlet TR, Dalmarco EM, Dalmarco JB, et al. (2012) Carvedilol attenuates oxidative stress in chronic chagasic cardiomyopathy. Arq Bras Cardiol 98: 218-224.

9. Nascimento BR, Lima MMO, Nunes MCP, Alencar MCN, Costa HS, et al (2014) Effects of exercise training on heart rate variability in patients with Chagas heart disease. Arq Bras Cardiol 201-208.

10. Daniel Franca Vasconcelo SDF (2012) Funcoes Autonômica Cardíaca e Mecânica Ventricular na Cardiopatia Chagásica Crônica Assintomática. Arq Bras Cardiol 98: 111-119. 